\title{
Prediction of Temperature and Precipitation in Damavand Catchment in Iran by Using LARS -WG in Future
}

\author{
Sepideh Karimi ${ }^{1, ~ *, ~ S a e e d ~ K a r i m i ~}{ }^{1}$, Ahmad Reza Yavari ${ }^{1}$, Mohamad Hosein Niksokhan ${ }^{2}$ \\ ${ }^{1}$ Department of Environmental Education, Management \& Planning, Faculty of Environment, University of Tehran, Tehran, Iran \\ ${ }^{2}$ Department of Environmental Engineering, Faculty of Environment, University of Tehran, Tehran, Iran
}

\section{Email address:}

sepidehkarimi@ut.ac.ir (S. Karimi), Irankarimis@ut.ac.ir (S. Karimi), ayavari@ut.ac.ir (A. R. Yavari), niksokhan@ut.ac.ir(M. H. Niksokhan)

\section{To cite this article:}

Sepideh Karimi, Saeed Karimi, Ahmad Reza Yavari, Mohamad Hosein Niksokhan. Prediction of Temperature and Precipitation in Damavand Catchment in Iran by Using LARS -WG in Future. Earth Sciences. Vol. 4, No. 3, 2015, pp. 95-100. doi: 10.11648/j.earth.20150403.12

\begin{abstract}
In recent years the issue of climate change and its effects on various aspects of the environment has become one of the challenges facing planners. It is desirable to analyze and predict the change of critical climatic variables, such as temperature and precipitation, which will provide valuable reference results for future water resources planning and management in the region. The aims of this study are to test the applicability of the Long Ashton Research Station Weather Generator (LARS-WG) model in downscaling daily precipitation and daily maximum (Tmax) and daily minimum (Tmin) temperatures in Damavand catchment in Iran and use it to predict future changes of precipitation and temperature. Future climate of the Damavand catchment is predicted by statistical downscaling outputs from General Circulation Models (GCMs) (HADCM3 for SRES A2 and B2 and A1B scenarios) for the period of 2046-2065.The results showed that the LARS-WG model produces excellent performance in downscaling Tmax and Tmin in the study region but compared to temperature, the model showed more error in downscaling daily precipitation. This issue was confirmed by examining the performance indicators including coefficient of determination, mean absolute error and root-mean square error. Also results showed that precipitation will decrease in future under these scenarios but temperature will increase. Findings of this study will serve as a reference for further studies and planning of future water management strategies in the Damavand catchment.
\end{abstract}

Keywords: Climate Change, Prediction, LARS-WG, Statistical Downscaling

\section{Introduction}

Today, the issue of climate change and its effects on various aspects of human life has become one of the most important environmental, political, economic and social issues. Climate change refers to any significant change in measures of climate lasting for an extended period (Giorgi, 2006). It is generally observed in the variations of temperature, precipitation, snow cover, sea level, atmospheric and oceanic circulation patterns, extreme weather events, etc. (Houghton et al., 2001). This phenomenon occurs when the climate of a specific area or planet is altered between two different periods of time (Eslamian, 2014). The globally averaged surface temperature data shows a linear warming trend of $0.85^{\circ} \mathrm{C}\left[0.65\right.$ to $\left.1.06{ }^{\circ} \mathrm{C}\right]$ during the period $1880-2012$. The total increase between the average of the $1850-1900$ period and the $2003-2012$ period is $0.78{ }^{\circ} \mathrm{C}$ [0.72 to $\left.0.85{ }^{\circ} \mathrm{C}\right]$, based on the single longest dataset available (IPCC, 2013). Changes in climate parameters such as precipitation and temperature will be coupled with adverse consequences, including flood, drought, loss of biodiversity and agricultural productions (Sayemuzzaman, et al., 2014; Taxak, et al., 2014). Thus, given the importance that climate change has and will have on the Earth's environment and its inhabitants it is necessary to take efforts towards further understanding of how climate change events occur. A well-established consensus by the climate change science community is that the downscaling of the raw output of climate change experiments from the Global Climate Model (GCM) is required for impact applications at regional to local scale (Pervez and Henebry, 2014). General circulation models (GCM), are models that have been developed in order to simulate the current climate of the earth, and are able to predict future climate change (Xu, 1999). These predictions are based on various scenarios, each representing a state of 
producing greenhouse gas emissions and factors affecting the production and the control of these gases. Some of the most famous general circulation models include: HadCM3, PCMI, MPI, CGCM3 and CSIRO-MK2. GCMs are considered to be the most reliable source providing the climate change information at coarse spatial resolution (Pervez and Henebry, 2014). However, a network which is defined for GCMs just covers few latitudes and longitudes. Thus, the output from these models does not apply at the local scale. To convert this data into applied basin-wide scales, down-scaling methods are used where, the large-scale data of general circulation models is converted to regional and local or station data (Xu, 1999). In general, there are two types of downscaling methods widely used to transform coarse scale information to finer scale: dynamic (physical) and statistical (empirical) downscaling (Chu et al., 2010; Karamouz et al., 2010; Wilby et al., 2004). Regional dynamical models have good spatial resolution for climate assessment and in which small-scale atmospheric and climate processes are somewhat involved, however, the use of these models is faced with time constraints of implementing the model (Babaeian and Najafi Nik, 2006). However, statistical approaches are preferable to dynamic methods because they are cost-effective, simple and fast in down-scaling and since these methods require fewer parameters than dynamical methods, they have received much attention in studies related to climate science (Wilby et al, 2004). In contrast, statistical downscaling builds relationships between large-scale climate variables (predictors) and local weather (predictands) based on the view that the regional climate is conditioned by two factors: large-scale climatic state and local/ regional physiographic features (Wilby et al., 2004). Some of the models used in statistical methods include: USCLIMATE WGEN, LARS-WG, CLIMGEN, GEM and SDSM. In recent years, several studies have been done on the effects of climate change and the prediction of climate variables using down-scaling statistical models in the world and in Iran that some of them are mentioned. Mavromatis and Hansen (2001) comparing WM, WM2 and LARS-WG models showed that LARS-WG model has produced data in a more acceptable level of confidence (95\%). Semenov (2008) using LARS- WG model studied temperature and precipitation at 20 stations in the UK, which were located in different climates. The results showed the high ability and accuracy of the model. Rajabi et al (2010) compared the results of two exponential down-scaling models SDSM and LARS-WG, in Kermanshah. The results showed the better performance of LARS-WG model in the study region. Chen et al (2013) used the LARS-WG model and the A2 scenario to predict precipitation, minimum temperature and maximum temperature in Sudan and South Sudan. The results showed the good performance of the model in predicting daily data. The aims of this paper are to test the applicability of the LARS-WG model in downscaling daily precipitation and daily maximum (Tmax) and daily minimum (Tmin) temperatures in Damavand catchment in Iran and use it to predict future changes of precipitation and temperature. So this study tries to answer the following questions: how does precipitation and temperature change in future? Awareness about the occurrence of precipitation and temperature changes in the future is necessary, given the ecological, aesthetic and socioeconomic importance of Damavand catchment and the important role that this catchment plays in the life of the region and the Central Watershed of Iran. In particular, it can be useful in environmental planning especially in water resources and drought programs, sustainable agriculture in the region, preventing seasonal flooding and prevention of soil erosion in the watershed.

\section{Study Area}

Damavand catchment is located in $51^{\circ} 56^{\prime}$ to $52^{\circ} 36^{\prime}$ of the east longitude and $35^{\circ} 45^{\prime}$ to $36^{\circ} 22^{\prime}$ of the north latitude. This basin is located in the southern region of Mazandaran Province and in term of the political division is a part of Amol County. The catchment area is 231,400 hectares. The minimum altitude of the basin is about 700 meters and the maximum altitude is 5610 meters. All rivers of the basin will end in River Haraz. Main rivers of the basin includes rivers Aachen sar, Shirkolarverd, Namarestagh. Important mountains of the basin are Mount Damavand, the highest area in the catchment area. The climate of the catchment based on Ambrish method ranges from semi-humid at slopes to semi-arid at mountains. The minimum precipitation occurred in the months of August and September and the maximum precipitation occurred in February and March. The coldest month is January and the warmest month is July (Forests,Range \& Watershed Management Organization of Iran,2011). Data required for the study consisted of daily precipitation, minimum temperature, maximum temperature and sunshine hours (which are referred to as observation data) in a thirty-year period (1983-2013). The data was received from Abali synoptic station with geographical coordinates of the east longitude of $51^{\circ} 59^{\prime}$ and the north latitude of $35^{\circ} 46^{\prime}$ and an altitude of 2246 meters above sea level, from meteorological agency. The station is the closest synoptic station to the area that has 30-year data of precipitation, temperature and sunshine hours in a daily scale.

\section{Methods}

\subsection{LARS-WG Model}

LARS-WG is a stochastic weather generator and is used for simulating weather data at a single site under both current and future conditions (Racsko et al. 1991; Semenov and Barrow 1997; Semenov and Stratonovitch 2010). The first version of the model was introduced in 1990 in Budapest, Hungary, and was revised in 1998 by Semenov. The model uses complex statistical distributions for modeling climate variables. LARS-WG uses observed daily weather data for a given site to compute a set of parameters for probability distributions of weather variables as well as correlations between them, which are used to generate synthetic weather time series of arbitrary length by randomly selecting values from the appropriate distributions. The first step in the production of synthetic data 
is the series modeling of wet and dry days. This model uses semi-empirical distribution to simulate wet and dry days, daily precipitation and solar radiation and this distribution is defined as a of cumulative probability distribution function.

$$
E P M=\left\{a_{0}, a_{i}, h_{i}, i=0, \ldots .10\right\}
$$

EMP is a histogram of the distribution of 10 different intervals (ai-1, ai) where ai- $1<$ ai (Semenov \& Barrow, 2002). The number of intervals used in semi-empirical distribution in the new version of the model is 23 compared to the previous version that used 10 , shows a more accurate representation of the observation distribution (Chen et al, 2013). In the semi-empirical distribution of radiation, the distance between minimum and maximum monthly radiation is equally divided. However, for dry and wet days and precipitation periods, the distance is increasing. Modeling of daily maximum and minimum temperatures is carried out by random processes with daily mean and standard deviations depending on whether day is wet or dry. The modeling of radiation is independent of temperature. Three-order Fourier series is used to simulate the seasonal mean and standard deviation of temperature. The values of remaining obtained by subtracting mean values from the observation values are used in time analysis of correlation between maximum and minimum data (Semenov \& Barrow, 2002). In LARS-WG, the process of generating synthetic weather data can be divided into three distinct steps, which are briefly described as follows.

\subsection{Model Calibration}

Model calibration is done to use the function "SITE ANALYSIS" in LARS-WG, which analyzes observed weather data (e.g., precipitation and the maximum and minimum temperature) to determine their statistical characteristics and stores this information in two parameter files (Chen et al,2013).

\subsection{Model Validation}

The parameter files derived from observed weather data during the model calibration process are used to generate synthetic weather data having the same statistical characteristics as the original observed data. Model validation is to analyze and compare the statistical characteristics of the observed and synthetic weather data to assess the ability of LARS-WG to simulate the precipitation, Tmax, and Tmin at the chosen sites in order to determine whether or not it is suitable for use in the study (Chen et al, 2013).

\subsection{Generation of Synthetic Weather Data}

The parameter files derived from observed weather data during the model calibration process can also be used to generate synthetic data corresponding to a particular climate change scenario simulated by GCMs (Chen et al, 2013).

As mentioned above, in order to predict weather data at a local scale, large-scale predictive data simulated by general circulation model are required. In the latest version of LARS-WG model (5), 15 General Circulation Models (GCM), all obtained from the fourth IPCC report (AR4), are included (Chen et al, 2013). In the present study, predictions of precipitation and temperature data are carried out using the outputs of HadCM3 model under three scenarios A2, B1 and A1B. HadCM3 Model is one the most famous general circulation models of the atmosphere developed at UKMHC7 Research Center in England with a spatial resolution of $2.5^{\circ} \times$ $3.75^{\circ}$ (Khadka et al, 2014). General circulation models do predictions based on scenarios. Each scenario is based on different assumptions about driving forces including demographic, technological and social and economic developments which are referred to as emission scenario. IPCC presented a new set of emission scenarios called SRES in a special report in 1996. In this report, 40 scenarios were presented for the future of the world in four main categories (A1, A2, B1, and B2) (IPCC, 2001). General specifications of the scenarios used in this study are provided in Table 1.

Table 1. $\mathrm{CO}_{2}$ concentrations for selected climate scenarios specified in the Special Report on Emissions Scenarios (Nakicenovic \& Swart 2000; Semenov \& Stratonovitch,2010).

\begin{tabular}{|c|c|c|c|c|}
\hline \multirow{2}{*}{ Scenario } & \multirow{2}{*}{ Key assumptions } & \multicolumn{3}{|c|}{$\mathrm{CO}_{2}$ concentration(ppm) } \\
\hline & & 2011-2030 & 2046-2065 & 2081-2100 \\
\hline & $\begin{array}{l}\text { Rapid change in economic structures, 'dematerialization' including improved } \\
\text { equity and environmental concern. }\end{array}$ & & & \\
\hline B1 'The sustainable world' & $\begin{array}{l}\text { There is a global concern regarding environmental and social sustainability and } \\
\text { more effort in introducing clean technologies. The global population reaches } 7 \\
\text { billion by } 2100 \text {. }\end{array}$ & 410 & 492 & 538 \\
\hline A1B 'The rich world' & $\begin{array}{l}\text { Characterised by very rapid economic growth ( } 3 \% \mathrm{yr}-1) \text {, low population growth } \\
(0.27 \% \text { yr }-1) \text { and rapid introduction of new and more efficient technology. } \\
\text { Globally there is economic and cultural convergence and capacity building, with } \\
\text { a substantial reduction in regional differences in per capita income. }\end{array}$ & 418 & 541 & 674 \\
\hline A2 'The separated world' & $\begin{array}{l}\text { Cultural identities separate the different regions, making the world more } \\
\text { heterogeneous and international cooperation less likely. 'Family values', local } \\
\text { traditions and high population growth }(0.83 \% \text { yr- } 1) \text { are emphasised. Less focus } \\
\text { on economic growth }(1.65 \% \mathrm{yr}-1) \text { and material wealth. }\end{array}$ & 414 & 545 & 754 \\
\hline
\end{tabular}

In the present study, to evaluate the performance of LARS-WG model and to ensure its ability to predict climate variables of temperature and precipitation, in addition to statistical tests (t-test, F-test and Chi-square) taking place in 
the model in the validation phase, performance indicators, coefficient of determination (R2), mean absolute error (MAE) and root mean square error (RMSE) are also used. Coefficient of determination is a dimensionless measure of which the best value is one. The model mean error and root mean square error represent the model error rate of which the best value is equal to zero (Khalili, 2012).

$$
\begin{gathered}
R^{2}=\frac{\left[\sum_{i=1}^{n}\left(X_{i}-\mu_{x}\right)\left(Y_{i}-\mu_{y}\right)\right]^{2}}{\sum_{\mathrm{i}=1}^{\mathrm{n}}\left(\mathrm{X}_{\mathrm{i}}-\mu_{\mathrm{x}}\right)^{2} \sum_{\mathrm{i}=1}^{\mathrm{n}}\left(\mathrm{Y}_{\mathrm{i}}-\mu_{\mathrm{y}}\right)^{2}} \\
\text { MAE }=\frac{\sum_{\mathrm{i}=1}^{\mathrm{n}}\left|\mathrm{X}_{\mathrm{i}}-\mathrm{Y}_{\mathrm{i}}\right|}{\mathrm{n}} \\
\text { RMSE }=\sqrt{\frac{\sum_{\mathrm{n}=1}^{\mathrm{n}}\left(\mathrm{X}_{\mathrm{i}}-\mathrm{Y}_{\mathrm{i}}\right)^{2}}{\mathrm{n}}}
\end{gathered}
$$

In the above equations $\mathrm{Xi}$ and $\mathrm{Yi}$ are $\mathrm{i}$-th observation and simulated data by the model, respectively. $\mathrm{x} \mu$ and $\mathrm{y} \mu$ are the average of all data of $\mathrm{Xi}$ and $\mathrm{Yi}$ in the study population and $\mathrm{n}$ is the number of all samples to be tested.

\section{Results and Discussions}

\subsection{Results of Calibration and Validation of Lars-Wg}

The daily data during the period of 1983-2013 were used to calibrate and validate the model for Abali station. In table 2, Results of the statistical tests showed at the $5 \%$ significance level. Results of the Chi-square test in Abali station show that P-Values of this test are situated in the null hypothesis acceptance for each three climatic variables, in all months. This means that the observed and synthetic data have the same frequency distribution. Also the t-test results concerning average precipitation, maximum temperature and minimum temperature indicate that the null hypothesis is acceptable with $95 \%$ confidence. In fact, the mean values of the observed and synthetic data are similar. F-test is used to compare the variances of the observed and synthetic data. But the LARS-WG, performs this test only for precipitation data; because precipitation data have high variability and don't follow a normal distribution. F-test result for the average precipitation parameter shows that the P-Value is more than 5\% for all months except for August and October, and the null hypothesis is acceptable on the basis of variances equality. Therefore, according to the obtained values we conclude that the performance of the model for simulation and prediction of the climatic variables of minimum and maximum temperatures is very good, and its performance concerning precipitation is at an acceptable level. Because, considering investigation on the main observational data in the region, it could be seen that there is a high distribution and changes in precipitation in these two moths. The coefficient of determination (R2) for temperature and precipitation variables calculated as $99 \%$ and $98 \%$ respectively. Minimum and maximum temperature variations indicate less error in terms of the root mean square error (RMSE) and mean of absolute error (MAE) (table 3). However, the value of these indices was calculated as high values for precipitation variable, which indicates the inappropriate performance of the model for simulation of the precipitation data and its cause could be originated from the high variability of the precipitation data in some months. Besides, the precipitation value is very low and in the study area (about a few mm) in year dry months (June, July, August, September), which can lead to errors in the performance of the model for prediction of the precipitation.

\begin{tabular}{|c|c|c|c|c|c|c|c|}
\hline \multirow{2}{*}{ Variables } & \multicolumn{2}{|c|}{ Maximum temperature } & \multicolumn{2}{|c|}{ Minimum temperature } & \multicolumn{3}{|c|}{ Precipitation } \\
\hline & t-test & Chi-Square test & t- test & Chi-Square test & F-test & T -test & Chi-Square test \\
\hline Jan & 0.668 & 0.998 & 0.518 & 0.999 & 0.744 & 0.427 & 1 \\
\hline Feb & 0.446 & 0.998 & 0.522 & 0.999 & 0.788 & 0.309 & 1 \\
\hline Mar & 0.389 & 1 & 0.846 & 1 & 0.081 & 0.941 & 1 \\
\hline Apr & 0.674 & 1 & 0.817 & 1 & 0.155 & 0.873 & 1 \\
\hline May & 0.102 & 1 & 0.176 & 1 & 0.018 & 0.875 & 1 \\
\hline Jul & 0.786 & 0.998 & 0.377 & 1 & 0.233 & 0.984 & 0.999 \\
\hline Aug & 0.638 & 0.998 & 0.697 & 0.999 & 0 & 0.18 & 0.453 \\
\hline Sep & 0.557 & 1 & 0.731 & 1 & 0.062 & 0.927 & 0.178 \\
\hline Oct & 0.649 & 1 & 0.66 & 1 & 0.002 & 0.572 & 1 \\
\hline Nov & 0.346 & 1 & 0.54 & 1 & 0.127 & 0.7 & 1 \\
\hline Dec & 0.367 & 1 & 0.507 & 1 & 0.639 & 0.977 & 1 \\
\hline
\end{tabular}

Table 2. Results of the statistical tests comparing the observed data for Abali station with 30 years of synthetic data generated through LARS-WG for the daily precipitation and daily maximum (Tmax) and daily minimum (Tmin) temperatures.

Table 3. Results of applicability of LARS-WG model by the performance indicators

\begin{tabular}{llll}
\hline Variables & R2 & MAE & RMSE \\
\hline Precipitation & 0.98 & 2.6 & 3.6 \\
Minimum temperature & 0.99 & 0.14 & 0.16 \\
Maximum temperature & 0.99 & 0.23 & 0.26 \\
\hline
\end{tabular}

\subsection{Generations of Future Climate Scenarios}

In the step of synthetic data generation, the model simulate the data of daily precipitation, minimum temperature, maximum temperature for the 2065-2046 period in Abali station, based on the data of calibration and validity evaluation steps, and also by using the output of HadCM3 atmospheric 
general circulation model. Results of this step show that for Abali station, the average annual precipitation in the period $2065-2046$ decreased by $8 \%$ in the A1B scenario, by $2 \%$ in A2 scenario, and by $7 \%$ in $\mathrm{B} 1$ scenarios, compared to the baseline (2013- 1983). Besides, the results are indicative of precipitation value increasing in February and December under all three scenarios and the decreasing in the other months (Fig. 1). Research results on the temperature show that the mean annual temperature will increase up to $2.8^{\circ} \mathrm{C}$ in the A1B scenario, by $1.2{ }^{\circ} \mathrm{C}$ in A2 scenario, and by $1.4{ }^{\circ} \mathrm{C}$ in $\mathrm{B} 1$ scenarios, compared to the baseline period (2013-1983) (Fig. 2).

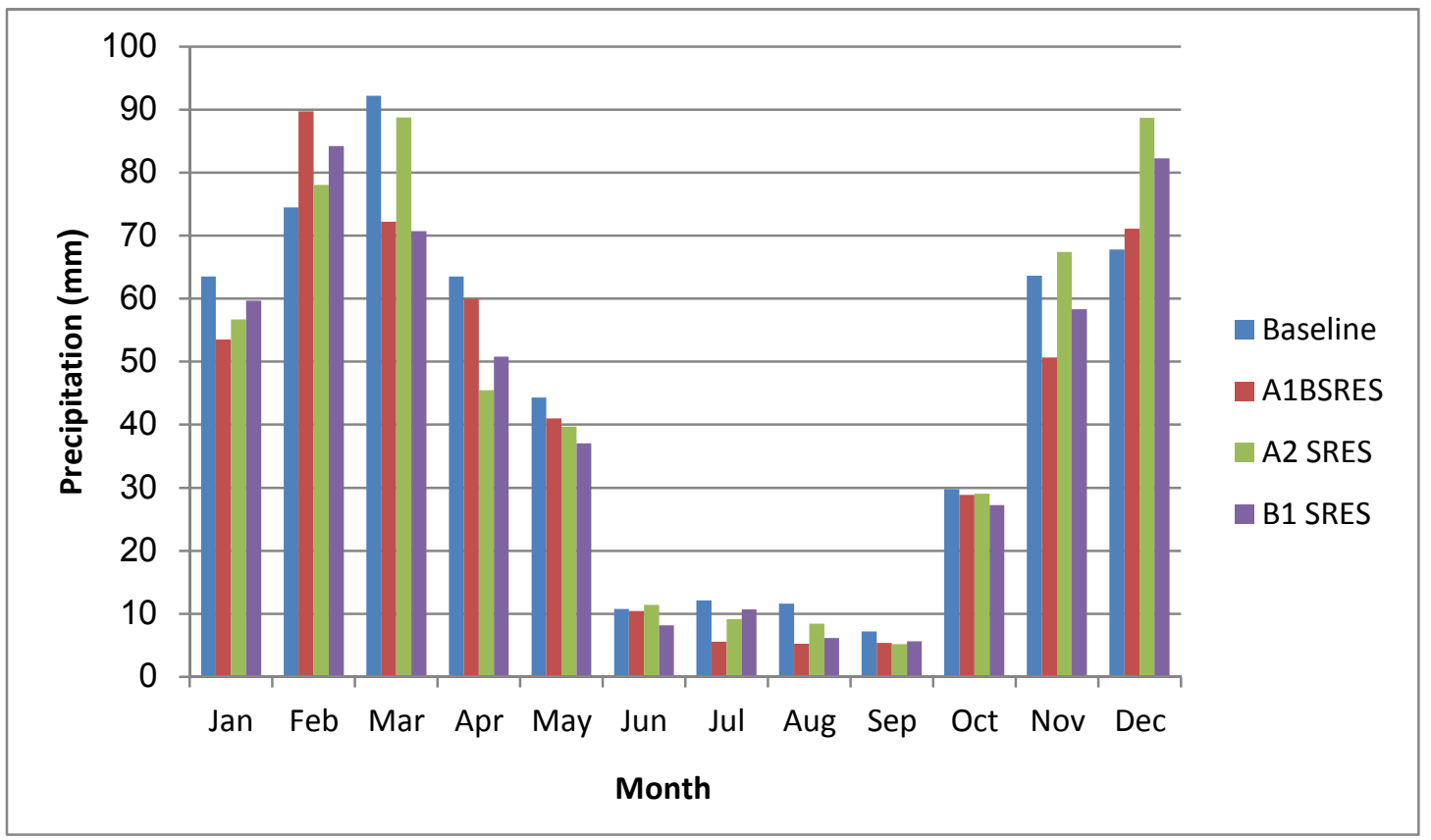

Fig. 1. A comparison of the observed mean monthly precipitation at Abali station to the LARS-WG-predicted values in the period 2046-2065.

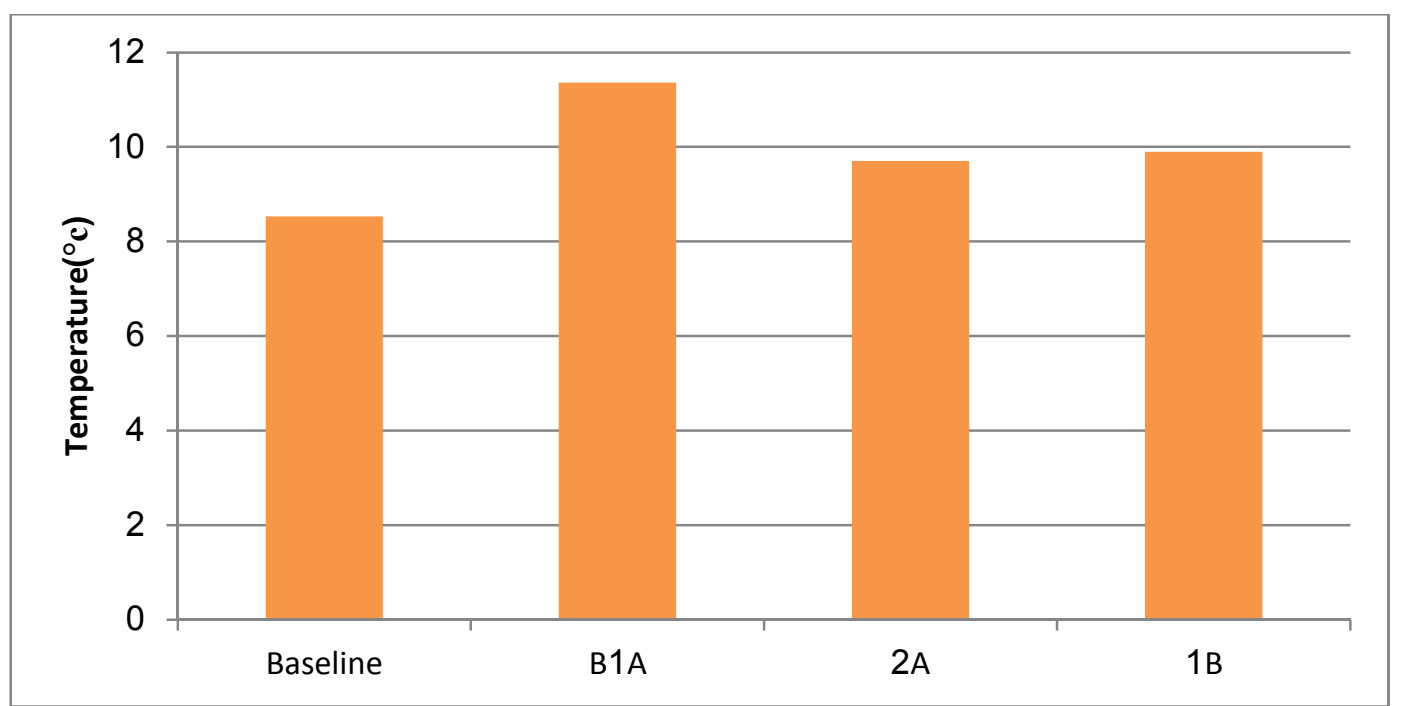

Fig. 2. A comparison of the observed mean monthly temperature at Abali station to the LARS-WG-predicted values in the period 2046-2065.

\section{Conclusions}

In the present study, we first tested the applicability of the LARS-WG model in downscaling daily precipitation and daily maximum (Tmax) and daily minimum (Tmin) temperatures in Damavand catchment and then used LARS-WG to downscale future changes of precipitation, Tmin, and Tmax from the HadCM3 outputs of SRA2, B1 and A1B scenario for the periods of 2011-2030 and 2046-2065.
Due to limitations of data availability, Abali stations of precipitation and temperature data for the period of 1983 to 2013 were used for calibrating the downscaling model and for comparison with future scenarios. From the study, it is concluded that:

- The LARS-WG model produces excellent performance in downscaling Tmax and Tmin in the study region but compared to temperature, the model showed more error in downscaling daily precipitation. This issue also 
confirmed by investigating on the functional parameters such as the coefficient of determination, mean of absolute error, root mean square error.

- The prediction results showed that the average annual precipitation in the 2065-2046 period in all three scenarios, namely A1B, A2 and B1, decreased up to $8 \%$, $2 \%$ and $7 \%$ respectively, compared to the baseline (2013- 1983).

- The mean annual temperature will increase up to $2.8^{\circ} \mathrm{C}$ in the $\mathrm{A} 1 \mathrm{~B}$ scenario, by $1.2^{\circ} \mathrm{C}$ in $\mathrm{A} 2$ scenario and by $1.4{ }^{\circ} \mathrm{C}$ in $\mathrm{B} 1$ scenarios.

\section{References}

[1] Babaeian,I , Najafi Nik, LARS-WG introduce and evaluate models for modeling of meteorological parameters province (1961-2003). Nivar journal ,63,Tehran,(2006), 66-49. (In Persian).

[2] Chen,H., Guo,J., Zhang,C. and Xu,C, Prediction of temperature and precipitation in Sudan and South Sudan by using LARS-WG in future, Springer, 113, (2013), 363-375.

[3] Chu, J. T., Xia, J., Xu, C.Y., Singh, V.P, Statistical downscaling of daily mean temperature, pan evaporation and precipitation for climate change scenarios in Haihe River, China. Theor. Appl. Climatol, 99, (2010), 149-161.

[4] [4] Eslamian,s.s , Handbook of Engineering Hydrology Modeling,Climate Change and Variability, Francis and Taylor,CRC Group,USA, 2, (2014), 646 .

[5] Forests,Range \& Watershed Management Organization of Iran. Watershed feasibility studies and natural resources, (2011).

[6] Giorgi, F, Climate change hot-spots. Geophys. Res. Lett, 33, (2006), 8 .

[7] Houghton, J.T., Ding, Y., Griggs, D.J., Noguer, M., van der Linden, P.J., Dai, X., Maskell, K., Johnson, C.A , Climate Change 2001: The Scientific Basis. Contribution of Working Group I to the Third Assessment Report of the Intergovernmental Panel on Climate Change. Cambridge University Press, Cambridge, UK/New York, USA, (2001).

[8] IPCC. Summary for Policymakers. In: Stocker, T.F., Qin, D., Plattner, G.-K., Tignor, M., Allen, S.K., Boschung, J., Nauels, A., Xia, Y., Bex, V., Midgley, P.M. (Eds.), Climate Change 2013: The Physical Science Basis. Contribution of Working Group I to the Fifth Assessment Report of the Intergovernmental Panel on Climate Change. Cambridge University Press, Cambridge, United Kingdom; New York, New York, USA, (2013).

[9] IPCC. The Scientific Basis of Climate Change. Contribution of Working Group I to the Third Assessment Report of the Intergovernmental Panel on Climate Change. Cambridge University Press. Cambridge, (2001), 67-68.

[10] Karamouz, M., Nazif, S., Fallahi, M., Rainfall downscaling using statistical downscaling model and canonical correlation analysis: a case study. In: Palmer, R.N. (Ed.), World Environmental and Water Resources Congress 2010: Challenges of Change-Proceedings of the World Environmental and Water Resources Congress 2010. American Society of Civil Engineers, Reston, (2010), 4579-4587.
[11] Khadka,D.,Babel,M.,Shrestha,S.,Tripathi,N, Climate change impact on glacier and snow melt and runoff in Tamakoshi basin in the Hindu Kush Himalayan (HKH) region .Journal of Hydrology 511, (2014), 49-60.

[12] Khalili \& et al. LARS-WG ability to predict the atmospheric parameters of Sanandaj .Journal of Research of Soil and Water Conservation, 4, (2012), 85-102.(In Persian)

[13] Mavromatis, Th., and Hansen, J.W , Inter annual variability characteristics and simulated crop response of four stochastic weather generators. Agricultural and forest meteorology, 109, (2001), 283-296.

[14] Massah Bavani \& et al, Detection of changes in temperature and precipitation in the previous periods, the ratio of the gases Glkhanh $\neg$ Ay (The case of West Azarbaijan province), Journal of the Earth and Space Physics, 3, (2013), 111-128. (In Persian)

[15] Nakicenovic N, Swart, R, Emissions scenarios. Special Report of the Intergovernmental Panel on Climate Change. Cambridge University Press, Cambridge, (2000).

[16] Pervez,M.S.,Henebry,G.M, Projection of the Ganges-Brahmaputra precipitation - Downscaled from GCM predictors. Journal of Hydrology,517, (2014), 120-134.

[17] Sayemuzzaman,M.,Manjo,K, Seasonal and annual precipitation time series trend analysis in North Carolina,United States. Atmospheric Research, 137, (2014), 183-149.

[18] Rajabi A. Sedghi H. Eslamian S. and Musavi H, Comparison of LARS-WG and SDSM Downscaling Models in Kermanshah (Iran). Ecology, Environment and Conservation ,16, (2010),465-474.

[19] Racsko P, Szeidl L, Semenov. M , A serial approach to local stochastic weather models. Ecol Model, 57, (1991), 27-41.

[20] Semenov, M.A., Barrow, E.M, LARS-WG: a stochastic weather generator for use in climate impact studies, (2002) http://www.rothamsted.ac.uk/masmodels/ larswg.php User Manual: 1-27.

[21] Semenov, M.A, Simulation of extreme weather events by a stochastic weather generator. Climate Research, 35, (2008), 203-212.

[22] Semenov, MA, Barrow EM , Use of a stochastic weather generator in the development of climate change scenarios. Clim Chang, 35,(1997), 397-414.

[23] Semenov, MA, Stratonovitch,P, Use of multi-model ensembles from global climate models for assessment of climate change impacts. Clim Res, 41, (2010), 1-14.

[24] Taxak,A.K.,Murumkar,A.R.,Arya,D.S , Long term spatial and temporal rainfall trends and homogeneity analysis in Wainganga basin, Central India, Weather and Climate Extremes, 4, (2014), 50-61.

[25] Wilby, R.L.,\& et al., Guidelines for Use of Climate Scenarios Developed from Statistical Downscaling Methods. Supporting material of the Intergovermental Panel on Climate Change, available from the DDC of IPPC TGCIA 27, (2004).

[26] Xu,c. climate change and Hydrological Models: A Review of Existing Gaps and Recent Research Development. Water Resources Management, 13, (1999), 369-382. 